\title{
Extracorporeal Life Support: Moving at the Speed of Light
}

\author{
Heidi J Dalton MD
}

\author{
Introduction \\ Patient Populations Treated With ECLS \\ Neonates \\ Pediatrics \\ Adults \\ Cardiac \\ Extracorporeal Pulmonary Resuscitation \\ Criteria for ECLS \\ Equipment Considerations \\ ECLS Systems \\ Cannulation \\ Sedation for the ECLS Patient \\ Summary
}

\begin{abstract}
Extracorporeal life support (ECLS), or extracorporeal membrane oxygenation (ECMO) as it is also known, has been used to support over 45,000 patients to date. Overall survival is $62 \%$. After many years of no change in equipment and technology, there has been a recent flurry of new pumps, cannulas, and oxygenators available for ECLS use. While the impact of this new technology is not yet completely defined, initial results have found that these systems provide safe support with lower priming volumes and less bleeding complications. New cannulas are also available, some making it easier for venovenous support in patients, from infants through adults. The reported success of ECLS in patients with H1N1 during the 2009-2010 epidemic and the improved survival of patients randomized to the ECMO arm of a recently completed adult study of respiratory failure have also brought ECLS into the spotlight much more than other years. Whether these developments will usher in a new era of ECLS expansion to a wider range of patients will require close consideration and observation. Other areas that need to be further refined include anticoagulation management, treatment of bleeding complications, learning to "nurse" patients in an awake state, such as is done in some European (and a few United States) centers, and neurodevelopmental outcome on a longterm basis. Key words: extracorporeal life support; ECLS; extracorporeal membrane oxygenation; ECMO. [Respir Care 2011;56(9):1445-1453. (C) 2011 Daedalus Enterprises]
\end{abstract}

Dr Dalton is affiliated with the Department of Critical Care Medicine, Phoenix Children's Hospital, Phoenix, Arizona.

Dr Dalton presented a version of this paper at the 47th RESPIRATORY CARE Journal Conference, "Neonatal and Pediatric Respiratory Care: What Does the Future Hold?" held November 5-7, 2010, in Scottsdale, Arizona.
The author has disclosed no conflicts of interest.

Correspondence: Heidi J Dalton MD, Department of Critical Care Medicine, Phoenix Children's Hospital, 1919 E Thomas Road, Phoenix AZ 85016. E-mail: hdalton@phoenixchildrens.com.

DOI: $10.4187 /$ respcare. 01369 


\section{Extracorporeal Life Support: Moving at the SpeEd of Light}

\section{Introduction}

Extracorporeal life support (ECLS) is a modified form of cardiopulmonary bypass that can provide temporary support of the pulmonary and/or cardiac circulation. Blood is withdrawn from the venous circulation into tubing that is connected to a servo-regulated pump (either a semiocclusive roller-head device or a centrifugal pump). ${ }^{1}$ Blood exits the pump head and is propelled to a membrane oxygenator, where carbon dioxide is removed and oxygenation occurs. Oxygenated blood is then rewarmed or cooled to the desired temperature and returned to the patient's circulation. In patients with adequate native cardiac function, blood may be both withdrawn and returned via the venous circulation of the patient. This mode of ECLS is termed venovenous and is predominant in patients who require support for refractory respiratory failure. Another mode of ECLS involves drainage of venous blood from the patient to the circuit, pump, and oxygenator, but the oxygenated blood is then returned to the arterial side of the patient's circulation. This type of support is termed venoarterial. As it bypasses both the heart and lungs of the patient, it is preferred in patients with primary cardiac failure or in patients with both cardiac and respiratory dysfunction.

The degree of support provided by ECLS is dependent on the caliber of cannulas used for venous drainage and arterial return, the size and resistance of tubing and circuit factors, and the quantity of blood diverted into the ECLS circuit. Physiologic factors such as the patient's available venous volume for bypass, systemic vascular resistance, and other physiologic factors also play a role into how much support ECLS can provide.

After many years of stagnation, the field of ECLS has seen an exponential rise in technology. Please note that ECLS and extracorporeal membrane oxygenation (ECMO) are used interchangeably in this paper. New cannulas, new pumps, new oxygenators, and associated devices have become available and are being adopted by many in the ECLS community. ${ }^{1,2}$ While at first blush these devices seem to be improvements over traditional systems, whether this turns out to be true will require further study and careful evaluation. ${ }^{1,3}$

\section{Patient Populations Treated With ECLS}

To date, over 45,000 patients have received ECLS. ${ }^{4}$ Patient populations as described in the International Registry for Extracorporeal Life Support are shown in Table 1. Overall survival is $62 \%$. Patients categorized as respiratory failure have the best survival, while patients receiving ECLS for cardiac etiologies or during cardiac arrest have much lower survival rates. Patients with multiple organ failure from any etiology, septic shock, burns, trauma,
Table 1. Overall Outcomes of Patients in the International Registry for ECLS

\begin{tabular}{lcrr}
\hline \hline & $\begin{array}{c}\text { Number of } \\
\text { Patients }\end{array}$ & $\begin{array}{c}\text { Survived ECLS, } \\
\text { no. (\%) }\end{array}$ & $\begin{array}{c}\text { Survived to Discharge } \\
\text { or Transfer, } \\
\text { no. (\%) }\end{array}$ \\
\hline Neonatal & & & \\
$\quad$ Respiratory & 24,344 & $20,608(85)$ & $18,276(75)$ \\
Cardiac & 4,232 & $2,566(61)$ & $1,663(39)$ \\
ECPR & 640 & $403(63)$ & $245(38)$ \\
$\begin{array}{l}\text { Pediatric } \\
\text { Respiratory }\end{array}$ & 4,771 & $3,094(65)$ & $2,656(56)$ \\
Cardiac & 5,221 & $3,322(64)$ & $2,502(48)$ \\
ECPR & 1,220 & $646(53)$ & $479(39)$ \\
Adult & & & $1,261(54)$ \\
Respiratory & 2,340 & $1,474(63)$ & $598(39)$ \\
Cardiac & 1,540 & $812(53)$ & $153(30)$ \\
ECPR & 516 & $201(39)$ & $27,833(62)$ \\
Total & 44,824 & $33,126(74)$ & \\
$\begin{array}{l}\text { ECLS }=\text { extracorporeal life support } \\
\text { ECPR }=\text { extracorporeal pulmonary resuscitation } \\
\text { (Data from Reference 4.) }\end{array}$ & & \\
\hline
\end{tabular}

airway abnormalities requiring complicated surgical repair, and immunocompromised patients all represent categories of disease that would have precluded ECMO use in the past but have been successfully supported with ECMO in more recent years. ${ }^{5-12}$

\section{Neonates}

While neonates with respiratory failure have formed the largest group of ECLS patients, advancement in prenatal and perinatal care, coupled with therapies and techniques such as inhaled nitric oxide, surfactant replacement, and high-frequency ventilation, have reduced the need for ECLS in many neonates with respiratory failure. ${ }^{13}$ Recognition and resolution of persistent pulmonary hypertension of the newborn with some of the therapies mentioned has decreased the need for ECLS in such patients.

Similarly, improvements in prevention and care of neonates with group B streptococcus infection have reduced the need for ECLS. Expansion of ECLS to neonates with other types of septic shock has occurred in recent years, although the finding that many of these patients have multiple organ failure at ECLS onset has been associated with decreased survival, as compared to the days when group B streptococcus was the instigating organism. Refractory cardiorespiratory failure from meconium aspiration syndrome has also declined, which is an additional factor in the reduced need for ECLS among neonates. Patients with congenital diaphragmatic hernia remain the neonatal population with the worst survival $(51 \%)$ and are most challenging to treat. ${ }^{4}$ 
Table 2. Demographics of Children Treated With ECMO for Acute Respiratory Failure, Relative to Outcome

\begin{tabular}{|c|c|c|c|c|}
\hline & $\begin{array}{c}\text { Survivors } \\
(n=1,824)\end{array}$ & $\begin{array}{l}\text { Nonsurvivors } \\
(n=1,389)\end{array}$ & $\begin{array}{c}\text { Survival } \\
(\%)\end{array}$ & $P$ \\
\hline \multicolumn{4}{|l|}{ Sex, no. (\%) } & .78 \\
\hline Male & 890 (49) & $695(50)$ & 56 & \\
\hline Female & $896(49)$ & $666(48)$ & 57 & \\
\hline Data missing & $38(2)$ & $28(2)$ & 58 & \\
\hline $\begin{array}{l}\text { Weight, median } \\
\text { (IQR), kg }\end{array}$ & $9(4-17)$ & $9.9(4.3-23)$ & & .003 \\
\hline \multicolumn{4}{|c|}{ Age Group, no. (\%) } & .001 \\
\hline $30 \mathrm{~d}$ to $1 \mathrm{y}$ & $880(48)$ & $661(48)$ & 57 & \\
\hline $1-5 \mathrm{y}$ & $513(28)$ & 329 (24) & 61 & \\
\hline $5-10 y$ & $165(9)$ & $133(10)$ & 55 & \\
\hline $10-18$ y & $266(15)$ & 266 (19) & 50 & \\
\hline
\end{tabular}

\section{Pediatrics}

Recently, the latest review of pediatric respiratory failure patients entered into the Extracorporeal Life Support Organization (ELSO) database ${ }^{14}$ compared patients who received ECMO from 1993-2007. Survivors had a lower median body weight, $(9.0 \mathrm{~kg}$ vs $9.9 \mathrm{~kg})$ and the median age was similar among survivors and nonsurvivors (Table 2). Older children (ages 10-18 years) had statistically $(P<.01)$ lower survival (50\%) than infants $(57 \%)$, toddlers $(61 \%)$, and younger children $(55 \%)$. While there has been little change in survival, patients with NO associated comorbidities had improved survival: 57\% in 1993 versus 72\% in 2007. One important note is that there was no significant decline in outcomes until patients reached a duration of ventilation prior to ECMO of $>14$ days. (Fig. 1). This is a large change from prior reports, which found that duration of ventilation for $>7$ days was associated with worse outcome. ${ }^{1}$ The use of high-frequency ventilation did not change over the period 1993-2007, and survival was not different between ventilation modes. (Table 3). Patients who received high-frequency ventilation, however, did have longer ventilation prior to ECMO than those who received conventional mechanical ventilation ( $4.6 \mathrm{~d}$ vs $3 \mathrm{~d}$ ). The oxygenation index was higher ( 48 vs $42, P<.001)$ and $\mathrm{pH}$ was lower $(7.27$ vs $7.31, P<.01)$ in non-survivors. Of note, pre-ECMO $\mathrm{pH}$ was progressively lower in both survivors and non-survivors as the years progressed. There was a trend toward increased use of venovenous ECMO, and venovenous ECMO was associated with improved outcome $(P<.01)$ (see Table 3$)$. When multivariate analysis to identify features associated with outcome were assessed, venovenous support had an odds ratio of

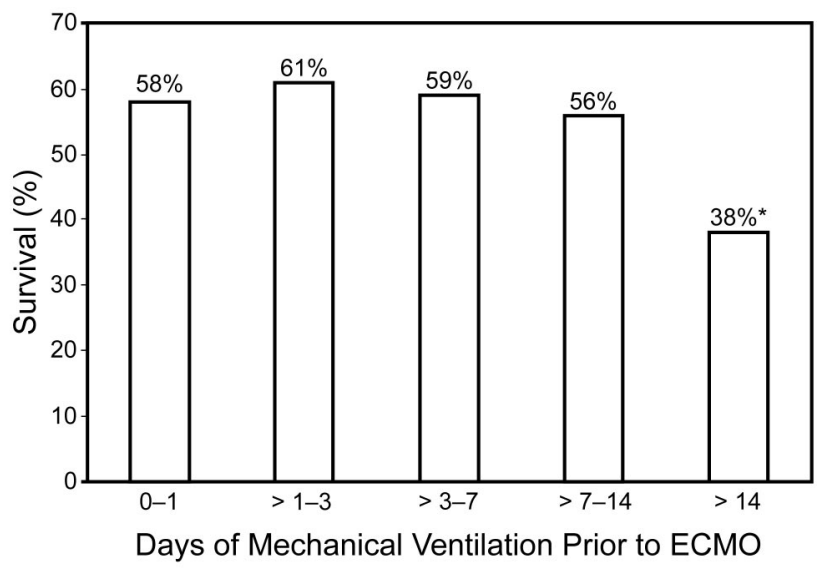

Fig. 1. Survival versus ventilation days prior to extracorporeal membrane oxygenation (ECMO). * Significant difference at $>14$ days, compared to the 0-1 day group. (Adapted from Reference 14, with permission.)

Table 3. Modes of ECMO and Ventilator Support Relative to Outcome

\begin{tabular}{|c|c|c|c|}
\hline & no. $(\%)$ & $\begin{array}{l}\text { Survival } \\
(\%)\end{array}$ & $P$ \\
\hline Pre-ECMO Ventilator Type & & & .70 \\
\hline Conventional & $1,569(49)$ & 58 & \\
\hline High-frequency & $1,233(38)$ & 56 & \\
\hline Other & $49(2)$ & 41 & \\
\hline Data missing & $362(11)$ & 58 & \\
\hline Pre-ECMO Ventilation Days & & & $<.001$ \\
\hline $0-1$ & $678(21)$ & 58 & \\
\hline$>1-3$ & $720(22)$ & 61 & \\
\hline$>3-7$ & $760(24)$ & 59 & \\
\hline$>7-14$ & $544(17)$ & 56 & \\
\hline$>14$ & $247(8)$ & 38 & \\
\hline Data missing & $264(8)$ & 53 & \\
\hline ECMO Mode & & & $<.001$ \\
\hline Venoarterial & $1,847(58)$ & 51 & \\
\hline Venovenous & $578(18)$ & 66 & \\
\hline Venovenous-double lumen & $509(16)$ & 70 & \\
\hline $\begin{array}{l}\text { Venovenous converted to } \\
\text { venoarterial }\end{array}$ & $195(6)$ & 49 & \\
\hline $\begin{array}{l}\text { Venoarterial converted to } \\
\text { venovenous }\end{array}$ & $16(5)$ & 63 & \\
\hline Data missing & $68(2)$ & 56 & \\
\hline Combined ECMO modes & & & $<.001$ \\
\hline All venoarterial modes & $2,042(64)$ & 51 & \\
\hline All venovenous modes & $1,103(34)$ & 67 & \\
\hline Data missing & $68(2)$ & 56 & \\
\hline
\end{tabular}

0.66 , as compared to patients with venoarterial cannulation. Table 4 shows the odds ratios for diagnosis, comorbidities, age, and pre-ECMO characteristics. As the ELSO 
Table 4. Multivariate Analysis of Factors Associated With Outcome

\begin{tabular}{|c|c|c|}
\hline & $\begin{array}{l}\text { Adjusted Odds } \\
\text { Ratio }\end{array}$ & $\begin{array}{c}\text { 95\% Confidence } \\
\text { Interval }\end{array}$ \\
\hline \multicolumn{3}{|l|}{ Diagnosis* } \\
\hline Asthma & 0.37 & $0.18-0.75$ \\
\hline Submersion & 0.50 & $0.23-1.10$ \\
\hline Pulmonary hemorrhage & 0.56 & $0.28-1.12$ \\
\hline Aspiration & 0.59 & $0.42-0.83$ \\
\hline Respiratory syncytial virus & 0.63 & $0.50-0.81$ \\
\hline ARDS, other & 0.93 & $0.32-2.68$ \\
\hline Pneumocystis & 1.20 & $0.49-2.90$ \\
\hline Acute respiratory failure & 1.29 & $1.04-1.61$ \\
\hline Other & 1.29 & $0.95-1.75$ \\
\hline ARDS, sepsis & 1.53 & $1.11-2.11$ \\
\hline Pertussis & 1.71 & $1.05-2.77$ \\
\hline Fungal pneumonia & 5.88 & $1.18-29.32$ \\
\hline \multicolumn{3}{|l|}{ Comorbidity } \\
\hline Renal failure & 2.20 & $1.68-2.89$ \\
\hline Primary immunodeficiency & 2.35 & $1.30-4.25$ \\
\hline Cardiac arrest & 2.25 & $1.35-3.74$ \\
\hline Cancer & 2.56 & $1.55-4.23$ \\
\hline Liver failure & 4.33 & $1.95-9.62$ \\
\hline \multicolumn{3}{|l|}{ Pre-ECMO Characteristics } \\
\hline Treatment before 2001 & 1.22 & $1.03-1.44$ \\
\hline Age $>10 y$ & 1.37 & $1.10-1.71$ \\
\hline Ventilation $>14 \mathrm{~d}$ & 2.55 & $1.90-3.42$ \\
\hline \multicolumn{3}{|l|}{ Pre-ECMO Blood pH } \\
\hline$<7.19$ & 1.53 & $1.24-1.88$ \\
\hline $7.19-7.29$ & 1.34 & $1.11-1.62$ \\
\hline$>7.29$ & 1 & Reference group \\
\hline \multicolumn{2}{|l|}{ ECMO Mode } & $0.996-0.999$ \\
\hline Venovenous & 0.66 & $0.56-0.77$ \\
\hline Venoarterial & 1 & Reference group \\
\hline \multicolumn{3}{|c|}{$\begin{array}{l}\text { * The reference group is bacterial pneumonia }+ \text { other viral pneumonia }+ \text { acute respiratory } \\
\text { distress syndrome (ARDS)-trauma/postoperative }+ \text { influenza }(n=1,060) \text {. Model } \\
\text { characteristics: } n=2,926, \text { Nagelkerke } R^{2}=0.60 . \\
\text { ECMO = extracorporeal membrane oxygenation } \\
\text { (Data from Reference 14.) }\end{array}$} \\
\hline
\end{tabular}

registry gives little detail on severity of illness prior to ECMO, outcome comparisons between venoarterial and venovenous ECMO may be difficult to interpret. One anecdotal comment that is common among clinicians is that ECLS is now being used in more complex and "sicker" patients than in years past. Gone are the days when a previously healthy child with overwhelming pneumonia would require ECLS - replaced now with patients with underlying disease complicated by a current illness. Patients with severe septic shock, cancer, burns, and various other conditions are now among those referred for ECLS. While experienced clinicians often initiate ECLS in such patients with good results, overall survival is not as good as with "simple" respiratory disease or single-organ failure.

\section{Adults}

Acceptance of ECLS as a useful support technique in adult patients has been slow. In the 1970s a National Institutes of Health-sponsored randomized trial of ECLS versus conventional mechanical ventilation found that ECLS was not superior to conventional care. ${ }^{15}$ That trial, however, was marred by the fact that patients in both groups had ventilator settings maintained at high levels $\left(\mathrm{F}_{\mathrm{IO}_{2}} 1.0\right.$ and high peak pressure) even if there were on ECLS. Excessive bleeding complications occurred in the ECLS group, and many of the centers involved had little to no prior ECLS experience. Nonetheless, the dismal survival rate of $9 \%$ in each group precluded the use of ECLS in adults in many clinicians' minds for many years. While there have been about 3,000 adults with respiratory failure placed on ECLS, the last few years have seen the largest increase. ${ }^{4}$

One exciting development has been completion and publication of the Conventional Ventilation or ECMO for Severe Adult Respiratory Failure (CESAR) trial. ${ }^{16}$ This was a randomized trial of adults in the United Kingdom who were randomized to conventional mechanical ventilation or transfer to one adult ECMO center (Glenfield Hospital, Leicester, England) if the inclusion criteria (based on a Murray score $>3$ or refractory hypercapnia with a $\mathrm{pH}$ $<7.20$ ) were met.

Of 180 patients entered into the CESAR trial (90 in the conventional group and 90 in the ECMO arm) survival at 6 months without disability in the ECMO arm was significantly better than the conventional arm (63\% vs $47 \%$, $P=.03$ ), with an estimated number-to-treat of 6 to achieve an additional life saved. The trial was stopped for efficacy at 180 patients by the data safety and monitoring board. An economic analysis from the study also found that ECLS patients met "acceptable" cost-adjusted quality-per-lifeyear costs of $£ 19,252$, comparable to other conditions such as breast cancer. ${ }^{16}$ Despite its dramatic results, controversy regarding the CESAR trial persists, especially regarding the fact that 17 of the 90 patients randomized to the ECMO arm did not receive ECMO. Those 17 patients were treated at the ECMO center, and their survival was 14 of 17 . While in the minds of the trial investigators (and those in the ECMO community), the finding that patients with severe respiratory failure had improved survival in the ECMO center whether or not they progressed to the need for ECMO validated the fact that clinicians in such centers provide optimal care for these patients-and that having ECMO as a tool in the algorithm of care adds a survival benefit. ${ }^{17}$ To others, this fact makes the trial results invalid because if the 17 patients who did not receive ECMO are removed from the analysis, the survival benefit from ECMO is not significantly different from conventional care. ${ }^{18}$

Another criticism of the CESAR trial is that patients cared for in the conventional sites did not receive a spe- 
cific algorithm of care, although use of low-tidal-volume, pressure-limited ventilation was advocated. Again, to many, the lack of mandated algorithmic care represents the true manner in which clinicians in the non-ECMO sites provide care and makes the study even closer to what happens in real life. To others, the lack of mandated algorithmic care means only that perhaps overall care in the ECMO center was better, and the use of ECMO had nothing to do with the better outcomes observed. Also of interest is that patients in the ECMO center received corticosteroids more than other patients. In summary, the CESAR trial provides great data and shows a positive benefit for ECMO use in adult respiratory failure, but also raises questions that need continued research and discussion.

On the heels of the publication of the CESAR trial came the H1N1 epidemic of 2009-2010. Early reports of survival in patients with severe respiratory or multiple organ failure due to H1N1 from Australia and sites where the epidemic hit prior to moving west to the United States and Canada created great interest in use of ECMO in adults. ${ }^{7,19}$ As there are only a few centers in the United States that provide adult ECMO, many ECMO centers were overwhelmed with requests for patient transfer. ELSO developed a Web site to collect data on patients receiving ECMO for H1N1 and maintained a United States bed board map that listed open centers with contact numbers (http:// www.elso.med.umich.edu). To date, 263 patients have been entered into the ELSO H1N1 database, with $63 \%$ survival. Two thirds of patients were over the age of 18 years.

Thus, renewed interest in use of ECMO in adults has led over the past year or so to the development of many new adult centers. While this is potentially good, lack of training and expertise in ECMO is a risk for inappropriate and non-optimal ECMO care. This factor emphasizes the continued need for ECMO centers to report their data to ELSO so that true representation of ECMO use and outcome can be continuously assessed. The ELSO organization has also developed fairly strict standards that allow centers to become recognized as "Centers of Excellence" if they meet specific training, quality-improvement, and organizational goals. The "Centers of Excellence" designation has now been accepted by groups such as the U.S. News and World Reports as a measure of quality in pediatric centers.

\section{Cardiac}

Perhaps the largest growing proportion of patients who are receiving ECLS are those with cardiac disease. ${ }^{4}$ Among all patients, neonates with underlying congenital heart disease form the largest group. While the majority of neonates are placed on ECLS for cardiac dysfunction following surgical repair, some also receive ECLS for preoperative stabilization or myocardial failure related to sepsis. While about $60 \%$ of neonatal cardiac patients are successfully weaned off ECLS, late deaths result in only about $39 \%$ survival to discharge. In pediatric cardiac patients (those over $30 \mathrm{~d}$ of age), congenital heart disease, myocarditis, and cardiomyopathy are underlying etiologies for ECLS. An ill-defined "other" subgroup category requires more specific description within the registry. Survival to hospital discharge among pediatric cardiac patients is about $48 \%$. Adult cardiac disease forms a fairly small part of the registry, as adults have a greater variety of assist devices to support cardiac failure than do smaller patients. The majority of adult cardiac patients are classified as "other" within the registry, with myocarditis and cardiomyopathy also forming some of the group. Survival to discharge among adult cardiac patients is about $39 \%$.

\section{Extracorporeal Cardiopulmonary Resuscitation}

A growing new category among ECLS patients is that of extracorporeal cardiopulmonary resuscitation (ECPR), which is ECLS applied during active cardiopulmonary resuscitation. ${ }^{4}$ The survival rate for this group of patients is $30-40 \%$. As ECPR is used for patients who are failing advanced cardiac life support and whose survival is likely to be close to zero, this result may create some optimism.

While duration of CPR prior to ECLS has not been proven to be associated with outcome in most recent studies, provision of adequate CPR efforts remains imperative. ${ }^{8,20-22}$ Further refinement of pre-ECLS factors that may predict outcome is a continuing area for focused research efforts. As with all areas of ECLS, data on short-term and long-term neurologic outcome and functionality of patients who survive ECLS following cardiac arrest is another area of needed investigation. As with all resuscitative rescue efforts, the goal of ECLS is not just to provide circulatory survival, but intact neurodevelopmental outcome as well.

One study that detailed the results of patients in cardiac arrest reported to the National Registry of Cardiopulmonary Resuscitation noted that $3.2 \%$ of 6,288 pediatric patients received ECLS. ${ }^{8}$ Survival to hospital discharge was $44 \%$. Of the 87 survivors, of whom 59 had neurologic assessment information available, 95\% were assessed as normal with the Pediatric Cerebral Performance Category Scale. When factors associated with impaired outcome were sought, pre-arrest renal insufficiency, presence of metabolic or electrolyte abnormalities at the time of arrest, and the use of sodium bicarbonate during resuscitation were identified by multivariate analysis. In that study the patients with preexisting cardiac disease had better outcomes than the medical patients without underlying cardiac disease prior to arrest. Another recent report found that duration of CPR prior to emergency ECLS was associated with poor outcome and neurologic morbidity. Among the 61 patients who received ECPR, the survivors had significantly shorter periods of CPR than those children 
who died (15 min vs $40 \mathrm{~min}, P=.009$ ). Patients with poor neurologic outcome also had longer durations of CPR (32 $\mathrm{min}$ vs $17.5 \mathrm{~min}, P=.03$ ). ${ }^{23}$

In another report, on 42 children who underwent ECPR (40\% survival), there were no differences between the patients with underlying cardiac conditions and those with other medical conditions. ${ }^{24}$ In that report, longer duration of CPR (30 min in survivors vs $46 \mathrm{~min}$ in non-survivors) and the need for multiple inotropes at high doses prior to arrest were associated with higher mortality. The duration of CPR in the 27 post-cardiotomy patients was $45.3 \pm 4.3 \mathrm{~min}$ versus $53.6 \pm 7.3 \mathrm{~min}$ in the 15 medical patients. $^{24}$

\section{Criteria for ECLS}

The complexity of patients now receiving ECLS makes it difficult to determine specific criteria for initiation. ${ }^{14,25,26}$ The oxygenation index, $\mathrm{P}_{\mathrm{aO}} / \mathrm{F}_{\mathrm{IO}_{2}}$, Murray score, and refractory hypercapnia with acidosis are used as general criteria for when ECLS should be considered in respiratory failure, although none are used as the only variable assessed for candidacy. ${ }^{27-29}$ While following these scores is helpful for trending severity of respiratory disease, the patient's overall status frequently requires case-by-case discussion among the care team to determine if the patient is a candidate for ECLS and when it should be initiated.

Among patients with septic shock and multiple organ failure, who are a growing subgroup that is both complex and difficult to manage, there are less data on criteria for implementation. Some suggestions are to follow the amount or dosage of vasoactive infusions, degree of organ dysfunction, and/or serial lactate levels. ${ }^{30-33}$ The recent publication of guidelines for hemodynamic support in infants and children lists ECMO as an option to be considered in patients who remain in shock following fluid resuscitation, vasoactive infusion administration, and corticosteroids, but specific markers to follow to aid in patient selection outside of hypotension are not provided. ${ }^{34,35}$ Similarly, ECLS for resuscitation during cardiac arrest is also listed as an option in the newly published guidelines for treatment of cardiac arrest in infants and children. ${ }^{36}$ One requisite for this approach is to have a functioning team that can provide emergency ECLS initiation in a timely fashion. Among cardiac patients, although no specific criteria have proven effective in every center, there have been multiple attempts to determine the variables associated with outcome. $33,37,38$

\section{Equipment Considerations}

\section{ECLS Systems}

Similar to the lack of specific criteria for ECLS candidates, there is inadequate standardization of the specifics of ECMO circuit design, cannulation techniques, and patient management strategies, although the general principles remain fairly constant. General guidelines for ECMO center training, equipment selection, patient selection, and clinical management were recently developed by expert consensus and are posted on the ELSO web site (http:// www.elso.med.umich.edu). While these guidelines are fairly general, they will, hopefully, enable more standardization of practice in the future across centers. ELSO also publishes several textbooks on extracorporeal support, which are valuable for more detailed information than this review can provide.

Traditionally, ECLS has been performed with a rollerhead (semi-occlusive) pump and a silicone membrane lung, which has been a reliable system for years. Because of the need for gravity drainage to augment venous return to the circuit, however, a siphon column between patient and circuit must be maintained. This had led many centers to use elevated bed height, with the low point in the venous circuit on the floor, to augment this siphon effect. As the roller head can generate high negative pressure, a servo regulation device is required. The shear stress on tubing in the roller head requires moving the tubing every few days to prevent weakening the tubing wall and potential rupture. Thus, extra tubing is built into the circuit to allow this procedure with minimal interruption to patient support. The silicone oxygenator is also difficult to prime to achieve adequate debubbling, a process that takes at least $20 \mathrm{~min}$. The high pressure generated after the roller head can also result in catastrophic tubing rupture if the post-roller-head portion of the circuit becomes occluded. These factors combine to make roller-head systems large in terms of circuit priming volume, slow to prime, and they require many safety devices to monitor pressures and flow.

Within the past 2 years a new series of centrifugal pumps have become available that have created a revolution in ECLS technology. These pumps have smaller priming volumes and work for days to weeks without requiring replacement. ${ }^{39,40}$ Polymethylpentene fibers have also allowed for new oxygenators that are highly efficient in gas exchange, have low resistance, and are easy to prime. The combination of these new pumps and oxygenators now allow circuits to be primed in minutes, with small priming volumes, and are much more convenient to use across a wide variety of patient sizes. The small priming volumes and ease of use make such systems preferable in many sites for initiation during cardiac arrest. Transport on ECLS is also much easier with these new systems. There are also theoretical considerations that these systems may be less hemolytic, require less anticoagulation, and generate less inflammatory response, although these facts have not yet been clinically proven in a rigorous, studied fashion.

Despite all these good points, however, centrifugal pumps can be dangerous, generating high levels of nega- 
tive pressure on the venous inlet side, resulting in cavitation and hemolysis or propagating air throughout the circuit (and potentially into the patient) if it gets past the centrifugal head and is not captured by the oxygenator. To lessen the risk of cavitation from excessive negative pressure, most centers employ a reservoir device such as the Better Bladder (Circulatory Technology, Oyster Bay, New York) that can help regulate pump function if the negative pressure limit is reached and lessen "peak and valley" pressure swings at the inlet and outlet of the centrifugal head. Such devices may also help trap air bubbles prior to reaching the centrifugal head.

Another new device is the Novalung (Novalung, Heilbronn, Germany), ${ }^{41}$ which is a polymethylpentene oxygenator that uses an arterial-venous shunt for access. It can provide about $1-1.5 \mathrm{~L}$ of blood flow without the need for an integrated blood flow pump. This is enough to provide total control of carbon dioxide and some improvement in oxygenation as well. Percutaneous access for cannula placement is often used. There are now multiple reports of patients being successfully bridged to lung transplant or recovery from pulmonary illness with the Novalung or pumpless extracorporeal lung-assist devices, and great videos and case histories of patients ambulating with this device with minimal need for sedation..$^{42-44}$

\section{Cannulation}

Traditionally, the majority of cannulations have been performed through the internal jugular/superior vena cava/ right atrium route for venous access. Arterial access is normally via the right common carotid artery to the arch of the aorta. In patients $>15 \mathrm{~kg}$, femoral vessels may be accessed for cannulation. In patients with prior recent sternotomy or cannulated in the operating room, direct cannulation of the right atrium and aorta can be performed, or the same cannulas used during cardiopulmonary bypass can be used for ECLS.

Associated with the changes in pumps and oxygenators, new cannulas and sites for cannulation have been promoted in the past couple of years. New cannulas have arrived that allow the use of venovenous ECLS in patients from newborn through adult using only one surgical site. ${ }^{45,46}$ Another interesting fact regarding cannulation is seen in several recent reports ${ }^{47,48}$ in which mediastinal cannulation in patients with severe septic shock was associated with improved outcome, when compared to other cannulation routes. In studies from the Australia-New Zealand Investigators network, 37 of 42 patients were cannulated for ECLS through the mediastinum. ${ }^{47,48}$ This factor was recently noted by others as associated with improved outcome. ${ }^{47,48}$ Of the 16 of 42 long-term survivors followed for months to years after ECLS, all were described as having good health and neurologic function, including 7 of 8 patients who had been bridged to heart transplant.

New designs of single cannula with double lumens for venovenous ECLS have also recently become available. One device is the Avalon (Avalon Laboratories, Rancho Dominguez, California), which is a wire-wrapped single cannula that has 2 venous drainage ports that sit in the superior vena cava/right atrial and inferior vena cava/right atrial junctions with the in-flow (returning blood to the patient) port directed at the tricuspid valve when the cannula is correctly placed. ${ }^{49,50}$ The cannulas range in size from 16 French to 32 French and have markedly less recirculation than earlier versions of venovenous cannulas. Despite these features, the cannula is somewhat difficult to place without fluoroscopic or echocardiographic guidance. Older versions of double-lumen single cannulas have had some problems with collapse of the venous return lumen with centrifugal pumps, and problems with kinking-a problem that seems poised to be resolved with newer production models soon to be in clinical trials. Percutaneous kits that do not require surgical cutdown, and improved dilator systems for easier cannula placement, have also improved ECLS cannulation and increased ECLS use in the adolescent and adult populations.

Changes in ECLS tubing surface coatings may limit blood-product destruction and decrease the inflammatory response during bypass initiation. These effects in turn may decrease activation of the coagulation cascade and may lessen the need for systemic anticoagulation. What effects this will have on the need for blood-product administration and bleeding, both of which are complications during ECMO, are not yet known.

\section{Sedation for the ECLS Patient}

Another new trend, just gaining ground, in ECLS is the movement to reduce sedation and increase patient mobility. ${ }^{51,52}$ While the traditional approach to ECMO management in the United States has been to keep the patient heavily sedated with narcotics or benzodiazepines to prevent inadvertent cannula dislodgement and other concerns, this is not the case in other areas of the world. Prolonged use of sedatives and narcotics, often at escalating doses due to dependence and resistance that develops over time, has been associated with increased risk of ventilator-associated pneumonia and skin breakdown from lack of normal movement. Further, prolonged hospitalization related to treatment of drug withdrawal occurs among ECMO patients and is a major adverse event.

Working with some of our Swedish and European colleagues to move toward less dependence on sedation and a more awake state offers many advantages for patient care and outcome. Some centers in the United States are making strides in this direction. Videos of both children 


\section{Extracorporeal Life Support: Moving at the SpeEd of Light}

and adults awake, out of bed, riding exercise bikes and participating in rehabilitative efforts while receiving ECLS are available and offer encouragement for this practice to grow. Further work needs to be done to make this an accepted and standard practice. The miniaturization of circuitry, new pumps, oxygenators, the increase in availability of cannulas that can be placed percutaneously, venovenous support, and advancements in patient management experience have all combined to make this the perfect time to allow patients to wake up, move, and perhaps even be extubated and off of mechanical ventilation during ECLS. ${ }^{53-55}$

\section{Summary}

The field of ECLS is moving forward at lightning speed. Continued technical advances are making ECMO safer, easier, and more widely available to patients, from neonates through adults. Better understanding of physiology and improved patient management continue to evolve. More research into anticoagulation techniques to prevent circuit clotting while also reducing bleeding complications is required. ${ }^{42}$ As it seems that use of ECLS techniques are on the rise, efforts to make it simpler, more efficient, safer, and most cost-effective should continue. Determining longterm neurodevelopmental outcomes for patients who receive ECLS should be a major goal for the future.

\section{REFERENCES}

1. Dalton HJ, Menon S. Extracorporeal life support. In: Fuhrman B, Zimmerman JJ. Pediatric critical care, 4th edition. Philadelphia: Elsevier Saunders; 2011:717-737.

2. Yamagishi T, Kunimoto F, Isa Y, Hinohara H, Morishita Y. Clinical results of extracorporeal membrane oxygenation (ECMO) support for acute respiratory failure: a comparison of a centrifugal pump ECMO with a roller pump ECMO. Surg Today 2004;34(3):209-213.

3. McMullan DM, Emmert JA, Permut LC, Mazor RL, Jeffries HE, Parrish AR, et al. Minimizing bleeding associated with mechanical circulatory support following pediatric heart surgery. Eur J Cardiothorac Surg 2011;39(3):392-397.

4. Extracorporeal Life Support Organization. ELSO registry information. http://www.elso.med.umich.edu/registry.html. Accessed July 12, 2011.

5. Fortenberry JD, Meier AH, Pettignano R, Heard M, Chambliss CR, Wulkan M. Extracorporeal life support for posttraumatic acute respiratory distress syndrome at a children's medical center. J Pediatr Surg 2003;38(8):1221-1226.

6. MacLaren G, Pellegrino V, Butt W, Preovolos A, Salamonsen R. Successful use of ECMO in adults with life-threatening infections. Anaesth Intensive Care 2004;32(5):707-710.

7. Gow KW, Lao OB, Leong T, Fortenberry JD. Extracorporeal life support for adults with malignancy and respiratory or cardiac failure: the Extracorporeal Life Support experience. Am J Surg 199(5):669675

8. Raymond TT, Cunnyngham CB, Thompson MT, Thomas JA, Dalton HJ, Nadkarni VM; for the American Heart Association National Registry of CPR Investigators. Outcomes among neonates, infants, and children after extracorporeal cardiopulmonary resuscitation for refractory in-hospital pediatric cardiac arrest: a report from the National Registry of Cardiopulmonary Resuscitation. Pediatr Crit Care Med 2010;11(3):362-371.

9. Hebbar KB, Petrillo-Albarano T, Coto-Puckett W, Heard M, Rycus PT, Fortenberry JD. Experience with use of extracorporeal life support for severe refractory status asthmaticus in children. Crit Care 2009;13(2):R29.

10. Lindén V, Karlén J, Olsson M, Palmér K, Ehrén H, Henter JI, Kalin M. Successful extracorporeal membrane oxygenation in four children with malignant disease and severe Pneumocystis carinii pneumonia. Med Pediatr Oncol 1999;32(1):25-31.

11. Thiagarajan RR, Roth S, Margossian S, Mackie AS, Neufeld EJ, Laussen PC, Forbess JM, Blume ED. Extracorporeal membrane oxygenation as a bridge to cardiac transplantation in a patient with cardiomyopathy and hemophilia A. Intensive Care Med 2003;29(6): 985-988.

12. Gow KW, Heiss KF, Wulkan ML, Katzentein HM, Rosenberg ES, Heard ML, et al. Extracorporeal life support for support of children with malignancy and respiratory or cardiac failure: the extracorporeal life support experience. Crit Care Med 2009;37(4):1308-1316.

13. Carey WA, Colby CE. Extracorporeal membrane oxygenation for the treatment of neonatal respiratory failure. Semin Cardiothorac Vasc Anesth 2009;13(3):192-197.

14. Zabrocki LA, Brogan TV, Statler KD, Poss WB, Rollins MD, Bratton SL. Extracorporeal membrane oxygenation for pediatric respiratory failure: survival and predictors of mortality. Crit Care Med 2011;39(2):364-370.

15. Zapol WM, Snider MT, Hill JD, Fallat RJ, Bartlett RH, Edmunds LH, et al. Extracorporeal membrane oxygenation in severe acute respiratory failure: a randomized prospective study. JAMA 1979; 242(20):2193-2196.

16. Peek GJ, Mugford M, Tiruvoipati R, Wilson A, Allen E, Thalanany $\mathrm{MM}$, et al; CESAR trial collaboration. Efficacy and economic assessment of conventional ventilatory support versus extracorporeal membrane oxygenation for severe adult respiratory failure (CESAR): a multicentre randomised controlled trial. Lancet. 2009;374(9698): 1351-1363. Erratum in: Lancet 2009;374(9698):1330.

17. Park PK, Dalton HJ, Bartlett RH. Point: Efficacy of extracorporeal membrane oxygenation in 2009 influenza A (H1N1). Chest 2010; 138(4):776-778.

18. Morris AH, Hirshberg E, Miller RR 3rd, Statler KD, Hite RD. Counterpoint: Efficacy of extracorporeal membrane oxygenation in 2009 influenza A (H1N1): sufficient evidence? Chest 2010;138(4):778781.

19. Cianchi G, Bonizzoli M, Pasquini A, Bonacchi M, Zagli G, Ciapetti $\mathrm{M}$, et al. Ventilatory and ECMO treatment of H1N1-induced severe respiratory failure: results of an Italian referral ECMO center. BMC Pulm Med 2011;11:2.

20. Morris MC, Wernovsky G, Nadkarni VM. Survival outcomes after extracorporeal cardiopulmonary resuscitation instituted during active chest compressions following refractory in-hospital pediatric cardiac arrest. Pediatr Crit Care Med 2004;5(5):440-446.

21. del Nido PJ, Dalton HJ, Thompson AE, Siewers RD. Extracorporeal membrane oxygenator rescue in children during cardiac arrest after cardiac surgery. Circulation 1992;86(5 Suppl):II300-II304.

22. Keckler SJ, Laituri CA, Ostlie DJ, St Peter SD. A review of venovenous and venoarterial extracorporeal membrane oxygenation in neonates and children. Eur J Pediatr Surg 2010;20(1):1-4.

23. Sivarajan VB, Best D, Brizard CP, Shekerdemian LS, d'Udekem Y, Butt W. Duration of resuscitation prior to rescue ECMO impacts outcome in children with heart disease. Intensive Care Med 2011; 37(5):853-860.

24. Delmo Walter EM, Alexi-Meskishvill V, Huebler M, Redlin M, Boettcher W, Weng Y, et al. Rescue extracorporeal membrane ox- 


\section{Extracorporeal Life Support: Moving at the SpeEd of Light}

ygenation in children with refractory cardiac arrest. Interact Cardiovasc Thorac Surg 2011;12(6):929-934.

25. Grist G, Whittaker C, Merrigan K, Fenton J, Pallotto E, Lofland G. Defining the late implementation of extracorporeal membrane oxygenation (ECMO) by identifying increased mortality risk using specific physiologic cut-points in neonatal and pediatric respiratory patients. J Extra Corpor Technol 2009;41(4):213-219.

26. Mehta NM, Turner D, Walsh B, Zurakowski D, Betit P, Wilson J, Arnold JH. Factors associated with survival in pediatric extracorporeal membrane oxygenation: a single-center experience. J Pediatr Surg 2010;45(10):1995-2003.

27. Trachel D, McCrindle BW, Nakagawa S, Bohn D. Oxygenation index predicts outcome in children with acute hypoxemic respiratory failure. Am J Respir Crit Care Med 2005;172(2):206-211.

28. Domico MD, Ridout DA, Bronicki R, Anas NG, Cleary JP, Cappon $\mathrm{J}$, et al. The impact of mechanical ventilation time before initation of extracorporeal life support on survival in pediatric respiratory failure: a review of the ELSO registry. Pediatr Crit Care Med 2011 [Epub ahead of print]

29. Iglesias M, Martinez E, Badia JR, Macchiarini P. Extrapulmonary ventilation for unresponsive severe acute respiratory distress syndrome after pulmonary resection. Ann Thorac Surg 2008;85(1):237244

30. MacLaren G, Butt W, Best D, Donath S, Taylor A. Extracorporeal membrane oxygenation for refractory septic shock in children: one institution's experience. Pediatric Crit Care Med, 2007;8(5):447-451.

31. Roch A, Lepaul-Ercole R, Grisoli D, Bessereau J, Brissy O, Castanier $\mathrm{M}$, et al. Extracorporeal membrane oxygenation for severe influenza A (H1N1) acute respiratory distress syndrome: a prospective observational comparative study. Intensive Care Med 2010;36(11): 1899-905.

32. Sivarajan VB, Best D, Brizard CP, Shekerdemian LS, D'Udekem Y, Horton SB, Butt W. Improved outcomes of paediatric extracorporeal support associated with technology change. Interact Cardio Vasc Thorac Surg 2010;11(4):400-405.

33. Hannan RL, Ybarra MA, White JA, Ojito JW, Rossi AF, Burke RP. Patterns of lactate values after congenital heart surgery and timing of cardiopulmonary support. Ann Thorac Surg 2005;80(4):1468-1474.

34. Brierley J, Carcillo JA, Choong K, Cornell T, Decaen A, Deymann A, et al. Clinical practice parameters for hemodynamic support of pediatric and neonatal septic shock: 2007 update from the American College of Critical Care Medicine. Crit Care Med 2009;37(2):666688.

35. Kissoon N, Orr RA, Carcillo JA. Updated American College of Critical Care Medicine pediatric advanced life support guidelines for management of pediatric and neonatal septic shock: relevance to the emergency care clinician. Pediatr Emerg Care 2010;26(11): 867-869.

36. Kleinman ME, Chameides L, Schexnayder SM, Samson RA, Hazinski MF, Atkins DL, et al; American Heart Association. Pediatric advanced life support: 2010 American Heart Association guidelines for cardiopulmonary resuscitation and emergency cardiovascular care. Pediatrics 2010;126(5):e1361-e1399.

37. Kane DA, Thiagarajan RR, Wypij D, Scheurer MA, Fynn-Thompson F, Emani S, et al., Rapid-response extracorporeal membrane oxygenation to support cardiopulmonary resuscitation in children with cardiac disease. Circulation 2010;122(11 Suppl):S241-2S48.

38. Kumar TK, Zurakowski D, Dalton H, Talwar S, Allard-Picou A, et al. Extracorporeal membrane oxygenation in postcardiotomy patients: factors influencing outcome. J Thorac Cardiovasc Surg 2010;140(2): 330-336.e2.

39. Kopp R, Bensberg R, Henzler D, Niewels A, Randerath S, Rossaint $\mathrm{R}$, Kuhlen R. Hemocompatibility of a miniaturized extracorporeal membrane oxygenation and a pumpless interventional lung assist in experimental lung injury. Artif Organs 2010;34(1):13-21.

40. Liebold A, Reng CM, Philipp A, Pfeifer rM, Birnbaum DE. Pumpless extracorporeal lung assist: experience with the first 20 cases. Eur J Cardiothorac Surg 2000;17(5):608-613.

41. McKinlay J, Chapman G, Elliot S, Mallick A. Pre-emptive Novalung-assisted carbon dioxide removal in a patient with chest, head and abdominal injury. Anaesthesia 2008;63(7):767-770.

42. Bein T, Osborn E, Hofmann HS, Zimmermann M, Philipp A, Schlitt HJ, Graf BM. Successful treatment of a severely injured soldier from Afghanistan with pumpless extracorporeal lung assist and neurally adjusted ventilatory support. Int J Emerg Med 2010;3(3): 177-179.

43. Wermelt JZ, Honjo O, Kilic A, van Arsdell G, Gruenwald C, Humpl T. Use of a pulsatile ventricular assist device (Berlin Heart EXCOR) and an interventional lung assist device (Novalung) in an animal model. ASAIO J 2008;54(5):498-503.

44. Ricci D, Boffini M, Del Sorbo L, El Qarra S, Comoglio C, Ribezzo $\mathrm{M}$, et al. The use of $\mathrm{CO}_{2}$ removal devices in patients awaiting lung transplantation: an initial experience. Transplant Proc 2010;42(4): 1255-1258.

45. Bermudez CA, Rocha RV, Sappington PL, Toyoda Y, Murray HN, Boujoukos AJ. Initial experience with single cannulation for venovenous extracorporeal oxygenation in adults. Ann Thorac Surg 2010; 90(3):991-995.

46. Sanchez-Lorente D, Go T, Jungebluth P, Rovira I, Mata M, Ayats MC, Macchiarini P. Single double-lumen venous-venous pumpdriven extracorporeal lung membrane support. J Thorac Cardiovasc Surg 2010;140(3):558-563, 563.e1-2.

47. ANZIC Influenza Investigators; Webb SA, Pettilä V, Seppelt I, Bellomo R, Bailey M, Cooper DJ, et al. Critical care services and 2009 H1N1 influenza in Australia and New Zealand. N Engl J Med 2009; 361(20):1925-1934.

48. MacLaren G, Cove M, Kofidis T. Central extracorporeal membrane oxygenation for septic shock in an adult with H1N1 influenza. Ann Thorac Surg 2010;90(3):e34-e35.

49. Javidfar J, Wang D, Zwischenberger JB, Costa J, Mongero L, Sonett $\mathrm{J}$, Bacchetta M. Insertion of bicaval dual lumen extracorporeal membrane oxygenation catheter with image guidance. ASAIO J 2011; 57(3):203-205.

50. Wang D, Plunkett M, Lynch J, Zhou X, Ballard-Croft C, Zwischenberger JB. Wang-Zwische double-lumen cannula leads to total cavopulmonary support in a failing fontan sheep model. Ann Thorac Surg 2011;91(6):1956-1960.

51. Wildschut ED, Hanekamp MN, Vet NJ, Houmes RJ, Ahsman MJ, Mathot RA, et al. Feasibility of sedation and analgesia interruption following cannulation in neonates on extracorporeal membrane oxygenation. Intensive Care Med 2010;36(9):1587-1591.

52. Turner DA, Cheifetz IM, Rehder KJ, Williford WL, Bonadonna D, Banuelos SJ, et al. Active rehabilitation and physical therapy during extracorporeal membrane oxygenation while awaiting lung transplantation: a practical approach. Crit Care Med 2011 (in press).

53. Ricci D, Boffini M, Del Sorbo L, El Qarra S, Comoglio C, Ribezzo $\mathrm{M}$, et al. The use of $\mathrm{CO}_{2}$ removal devices in patients awaiting lung transplantation: an initial experience. Transplant Proc 2010;42(4): $1255-1258$

54. Haneya A, Philipp A, Mueller T, Lubnow M, Pfeifer M, Zink W, et al. Extracorporeal circulatory systems as a bridge to lung transplantation at remote transplant centers. Ann Thorac Surg 2011;91(1): 250-255.

55. Olsson KM, Simon A, Strueber M, Hadem J, Wiesner O, Gottlieb J, et al. Extracorporeal membrane oxygenation in nonintubated patients as bridge to lung transplantation. Am J Transplant 2010;10(9):21732178. DOI: $10.1111 / \mathrm{j} .1600-6143.2010 .0319 . x$. 


\section{Discussion}

Branson: The H1N1 experience in Australia was published, ${ }^{1}$ and ECMO was widely used, but I think most of the ECMO patients died of ECMO complications. What do you think about the idea of venoarterial ECMO with the Novalung?

1. ANZIC Influenza Investigators; Webb SA, Pettilä V, Seppelt I, Bellomo R, Bailey M, Cooper DJ, et al. Critical care services and 2009 H1N1 influenza in Australia and New Zealand. N Engl J Med 2009;361(20):19251934.

Dalton: The Novalung is a hot new device. It's an oxygenator made of polymethylpentene, and it has very low resistance to blood flow and excellent gas exchange. You run it with an arteriovenous shunt through the femoral vessels. You cannulate the femoral artery and femoral vein and you can get 1-2 $\mathrm{L}$ of cardiac output in an adult. Novalung does a good job with $\mathrm{CO}_{2}$ removal. It can remove anybody's $\mathrm{CO}_{2}$-for instance, in patients with COPD, and most COPD patients eventually die because of suffocation from elevated $\mathrm{P}_{\mathrm{CO}_{2}}$ or pneumonia that goes along with their chronic lung disease.

The Novalung has been very effective. I've seen movies of patients up and walking around with it. It's been used as a bridge to transplant for patients awaiting lung transplant, and for patients who just need a little bit of support. It doesn't oxygenate as well as full ECMO, obviously, but the $\mathrm{CO}_{2}$ removal allows you to drop the ventilator settings or even take the patient off the ventilator.

About H1N1, I don't remember the statistics on that, but you're probably right. Certainly ECMO complications are pretty substantial. A lot of the patients they put on were pretty sick and had a lot of bleeding complications. Bleeding is a big problem because ECMO requires anticoagulation.

Willson: Heidi, we don't do ECMO very often any more for respiratory failure, but we seem to be doing it more with cardiac kids. One of the things we always ask about kids coming back from the operating room is how long were they on bypass. There's an implication that the longer they're on bypass, the worse they're going to do, and the treatment for that is to go on ECMO, which is effectively very similar to bypass. What is it about being on ECMO that allows a child who won't come off bypass in the operating room 3 days later can come back off on ECMO?

Dalton: Quite a few studies have shown that duration of bypass adversely affects outcome. However, there are also studies that say time on bypass isn't important as a prognostic indicator. There are several things about bypass. First, patients on full cardiopulmonary bypass are quite heparinized. Those kids have activated clotting time of well over a 1,000 seconds. In ECMO we use activated clotting time of 180 to maybe $200 \mathrm{sec}-$ onds. So an ECMO patient's bleeding risk is a lot less than a patient who's on cardiopulmonary bypass.

Second, the way we do it is a lot different. In full cardiopulmonary bypass, you bypass the lungs totally, and a lot of people believe that when you're draining blood out of the left heart as well that the re-perfusion injury when the lungs are re-perfused is what is responsible for a lot of the capillary leak and inflammatory response that we see after bypass. ECMO only does partial bypass: it lets some blood go through the lungs, provides good tissue oxygenation, and basically buys the heart time to recover.

I think that in the old days the concern was that coming out of the operating room on ECMO was associated with death, surgeons would try revising operations or whatever to allow the patient to eventually get weaned off bypass prior to coming to the ICU. Patients would end up with such prolonged bypass times, their outcomes were really poor. Now we know that if you are satisfied with your repair, it's better to put them on ECMO in the operating room to shorten their total cardiopulmonary bypass time, and outcomes have improved. This is another aspect of bypass we don't talk a lot about. Many patients don't come off bypass because their repair is inadequate, and we've learned that if they leave the operating room with a residual lesion, the outcome is worse.

So there is a conundrum for surgeons: if their initial repair is inadequate, they have to go back on bypass to repair it, and this often allows more organ dysfunction to occur from the effects of prolonged bypass. If you don't leave the operating room with a good repair, but you have a shorter bypass time, kids also don't do so well.

I think physiologically there is a big difference between cardiopulmonary bypass and ECMO support. Part of it is the amount of heparin you need. Part of it is the blood flow that you get because you let blood go through the heart/lung network pretty normally. If your center has a cardiac surgeon who wants to start doing ECMO, there's a learning curve even for cardiac surgeons, because they think ECMO is just like bypass, but it's not. You're not actually venting the left heart. And venoarterial ECMO is actually worse on the heart because it increases afterload. It might not always work, but it seems to help some kids, and we definitely need more specifics to figure out the factors involved in outcome.

Curley: Do you have data on functional outcomes for these kids, rather than just survival data?

Dalton: There are not a lot of data. I'm interested in looking at transfusions and bleeding on ECMO, because it's not been very well described in a large patient population. Part of that will be looking at one-year outcome at least. There are more outcome data on cardiac patients who have received 
ECMO than there are for respiratoryfailure patients.

I think the biggest need for ECMO and the pediatric ICU in general is outcomes research. We need to gear that up. Just like they're finding in congenital heart disease now: if I had a kid who had a horrible congenital heart disease, I have to tell you that I was always going to pick transposition. It seemed pretty simple: you switch the vessels around and they seem fine. But now we know a lot of those kids have abnormal brains from the get-go. That's what we need to be looking at as a specialty: long term outcome.

As an example, a few years ago, fentanyl was touted as one of the ways to improve outcome in cardiac kids at risk for postoperative pulmonary hypertension, but recently there were reports that sedatives and narcotics are associated with neurologic damage in infants. I'm not sure how to get all the work funded, but I do know that we need to make post-ICU outcome research more of priority.

In Sweden they nurse most of their ECMO patients completely awake, but they haven't done a lot of long-term testing either. They look at the kids as they go out the door in terms of acting or not acting normally. With a 10year-old you can probably do that pretty accurately, but with a one-yearold it's hard. But if you look at some of the data coming from CHOP [Children's Hospital of Philadelphia] and other sites, there are a lot of subtle neurodevelopmental defects being noted in cardiac patients. I'd be glad to write a grant with you to look into outcome, as there is a definite need for further information and research.

DiBlasi: You cited many of the ventilation modes that were being implemented prior to patients being placed on ECMO, but what about after they were placed on the pump or when they're being weaned from the pump? I can recall patients who were stuck on venoarterial ECMO, and we changed the ventilator mode three different times over two days. I've gone from conventional to high-frequency to airway pressure-relief ventilation to try to recruit their lungs. Are there any disease-specific management strategies for optimizing ventilator support in ECMO patients? Do institutions report to ELSO these different ventilator strategies?

Dalton: That's a million dollar question. No, ELSO doesn't record that, although we should. ELSO's management guidelines are posted on their Web site. Most of us believe that rest settings on the ventilator would be something that equates to the peak inspiratory pressure-a plateau of less than $30 \mathrm{~cm} \mathrm{H}_{2} \mathrm{O}$. And most of us in pediatrics tend to use a PEEP of 10 $15 \mathrm{~cm} \mathrm{H}_{2} \mathrm{O}$ and a few spontaneous breaths.

In Sweden all the kids-and often the adults-are on pressure support and CPAP, and some are not on a ventilator at all. Spontaneous breathing is supposed to be the way to go, but I think we're not good enough with sedation yet in the United States. You have to get through this period of when they're waking up and they're fighting the ventilator and the flow won't go and people are screaming at you to do different things. In other countries, they sort of start them out on a little morphine but they have a lot of distraction therapy to keep these kids so they're spontaneously breathing.

I'm a fan of the oscillator preECMO, but I take them off the oscillator when I put them on ECMO. I think you can't tell what you're doing on the oscillator while you are on ECMO. You can't follow the tidal volumes, spontaneous breaths, or $\mathrm{CO}_{2}$ elimination, and they often need more sedation. If you believe that ECMO is sort of replacing a lot of their ventilator needs, then why do you need the oscillator? When I'm taking a difficult patient off ECMO, I consider the oscillator one of my tools if I can't get the patient off with adequate ventila- tion and oxygenation on conventional ventilation. If I take the patient off on high-frequency ventilation, I'm already using off one of my backup tools. If the patient deteriorates off ECMO while on the oscillator, I don't have a lot else to offer, short of putting them back on ECMO.

I feel the same way about nitric oxide. Actually, I feel that NO doesn't work. It's an expensive, unproven therapy pre-ECMO, and even less is known if you use it to get a respiratory-failure patient off support. So I don't use the oscillator. I do bronchoscopy on a lot of patients on ECMO, to try and get out secretions as time goes on, and I try to be patient. A lot of us have tried fancy things like following compliance measurements and $\mathrm{V}_{\mathrm{T}}$, but it seems to me that as the kids who are on for respiratory failure are getting better, their chest X-ray clears up, their tidal volume increases, and they can be weaned. I advocate low peak inspiratory pressure, high PEEP, and spontaneous breathing.

Myers: You showed some encouraging-I won't say promising, but encouraging - data on H1N1 in cardiac patients. I think those patients get sick very quickly, and we need to make quick decisions. Do you think that some of the high mortality outcomes are because we drag our feet with some of those patients, because ECMO is still a big deal because it's invasive, and we don't put some of those patients on it soon enough?

Dalton: Yes, without a doubt, I believe that's true. And I have done the same thing myself. Sometimes you think you can wait another hour and reassess, and then it turns out to be hours later when you finally decide to initiate. I am not certain that hesitation benefits the patient, although there is also the corollary that if you put the patient on too soon, you may be criticized as well. That's why I think looking at serial markers of perfusion, oxygenation, et cetera, and setting some 
cutoffs may prove to be useful as we move forward.

Certainly if you look at the statistics, in every study, patients who went on ECMO sooner rather than later did better. The rebuttal to that could be "they weren't that sick and you probably didn't need to put them on in the first place, and you're a wimp for putting them on early." But I think it makes a big difference, certainly in H1N1. In Australia they put a lot of folks on fairly early.

We had 3 patients at Phoenix Children's Hospital in one week, and all of them were on within the first 24 hours because we thought they needed it. The 16-year-old I presented was almost dead within a few hours of admission. We had an 8-year-old with cerebral palsy who also had really bad respiratory failure within a day. And we had a 2-month-old ex-preemie with a tracheostomy for subglottic stenosis who had horrible air leak within the first 12 hours. All of them were put on within the first 24 hours and all of them survived, although that baby was on for 38 days before she finally got better. I was afraid to walk by the bedside because people were looking at me funny-wondering when we were going to stop. At team meetings we repeatedly said, "OK, has anything changed? Nope. Her brain's still good, her heart's still good, her kidneys are still good, and her lungs are still terrible. Let's try another week." All of a sudden she got off, and she came back to see her pediatrician, who called us to say that her tracheostomy was out and she was running around doing great.

Cheifetz: It was so good to see awake children on ECMO, in that picture you showed. I believe many ECMO patients are over-sedated because a care provider believes that the child should be sedated, rather than that there is a real clinical need for additional sedation for safety or comfort. Recently at Duke we had with three adolescents with end-stage cystic fibrosis who were admitted for lung-transplant evaluation, and our transplant surgeons said that if these patients were on the ventilator and sedated for more than one week, they would not be transplant candidates. So we cannulated them for ECMO, placed a tracheostomy within 24 hours, woke them up, and had them ambulating on venovenous ECMO prior to transplantation. ${ }^{1}$ Our experience with these patients is that the post-transplant course can be shortened with such an approach. A key question is whether a similar approach could be employed for ARDS? Of course, such an approach may require continued positive-pressure ventilation to keep the lungs open. Could that be possible?
1. Turner DA, Cheifetz IM, Rehder KJ, Williford WL, Banuelos SJ, Lin SS, et al. Active rehabilitation and physical therapy during extracorporeal membrane oxygenation while awaiting lung transplantation: a practical approach. Crit Care Med 2011 [in press].

Dalton: I would love to do that, but I think sedation is a completely nursing-driven practice. When you get 10 calls in one night because the patient is moving, you give up and order more sedation. I think when the nurses buy into it and want to do it, it will happen. Maybe 15 years ago I had a nurse taking care of a 26-year-old woman on ECMO with septic shock, and she kept the patient awake enough for her request that her hair be washed. I thought that was great, and your stories are more evidence that we should advocate for less sedation. The one thing that bothers me is the recent study $^{1}$ that found that paralytics in ARDS may be beneficial. For 10 years I've been preaching to residents and fellows on the evils of paralytics, and now that paper appears to spite this line of thinking. We need more data, but, yes, I think we should wake them up.

1. Papazian L, Forel JM, Cacouin A, PenotRagon C, Perrin G, Loundou A, et al; ACURASYS Study Investigators. Neuromuscular blockers in early acute respiratory distress syndrome N Engl J Med 2010; 363(12):1107-1116. 